\title{
Impacto da Assimilação de Dados de Radar em Sistemas Convectivos de Mesoescala: Um Estudo de Caso
}

\author{
Rute Costa Ferreira ${ }^{1}$, Dirceu Luis Herdies ${ }^{1}$, Éder Paulo Vendrasco ${ }^{1}$, \\ César Augustus Assis Beneti ${ }^{2}$, Thiago Souza Biscaro ${ }^{1}$ \\ ${ }^{1}$ Centro de Previsão do Tempo e Estudos Climáticos, Instituto Nacional de Pesquisas Espaciais, \\ Cachoeira Paulista, SP, Brasil. \\ ${ }^{2}$ Instituto Tecnológico Simepar, Curitiba, PR, Brasil.
}

Recebido em 31 de Janeiro de 2017 - Aceito em 7 de Maio de 2017

\begin{abstract}
Resumo
Este trabalho apresenta um estudo de um sistema convectivo de mesoescala com base na assimilação de dados de radar. Diversas simulações foram realizadas a partir do uso de dados de refletividade e velocidade radial dos radares de Cascavel e Assunção. Foram feitas rodadas com o WRF sem assimilação, com assimilação de dados convencionais e com assimilação de dados de radar e comparadas com estimativa de precipitação combinada (CoSch3). A rodada com assimilação de dados de radar inseriu ao modelo a velocidade radial e a refletividade de maneira indireta, ou seja, assimilou a razão de mistura de água de chuva. As novas análises geradas a partir da assimilação de dados mostraram o impacto da assimilação de radar desde baixos a altos níveis da atmosfera, assim como no perfil vertical. A utilização de ciclos para inicialização do modelo mostrou-se imprescindível para melhoria na previsão do posicionamento da precipitação. Dentre as configurações de previsão de precipitação, a assimilação de dados de radar mostrou uma melhoria ao prever os núcleos de precipitação intensa. Os resultados deste trabalho podem contribuir para melhorar os sistemas de alerta deste tipo de evento com maior precisão espacial e temporal.
\end{abstract}

Palavras-chave: SCM. WRFDA. Modelagem Atmosférica. 3DVAR.

\section{Impact of Radar Data Assimilation in a Mesoscale Convective System: A Case of Study}

\begin{abstract}
A study of a mesoscale convective system using radar data assimilation is presented. Simulations were made using reflectivity and radial velocity data from two radars (Cascavel and Asunción). Different initializations of the WRF-model were performed: without assimilation, with assimilation of conventional data, and with assimilation of radar. Results were compared with CoSch3 precipitation estimates. Reflectivity and radial velocity data were introduced to the model indirectly (by assimilating rain water mixing-ratio). Analysis generated from the data assimilation showed the impact of the radar data assimilation throughout the model vertical structure. We demonstrated that using cycles to initialize the model is fundamental to improve rainfall location forecasts. Assimilating radar data proved to be the best results to forecast intense precipitation cores. The results may contribute to improve early warning systems.
\end{abstract}

Keywords: MCS. WRFDA. Atmospheric Modeling. 3DVAR.

\section{Introdução}

Os Sistemas Convectivos de Mesoescala (SCM) são sistemas que se formam rapidamente e são caracterizados por grandes volumes de precipitações que ocorrem durante um curto período de tempo. Por isso, os modelos de Previsão Numérica do Tempo (PNT) têm dificuldades em prever a precipitação relacionada ao sistema, sendo possível detectar a sua ocorrência com algumas horas de antecedência. Embora a evolução de um SCM não seja bem prevista pela modelagem, esta área de pesquisa tem conseguido avanços significativos com o aumento da capacidade computacional e de pesquisas científicas em áreas

Autor de correspondência: Rute Costa Ferreira, ferreira.rutec@gmail.com. 
relacionadas a modelagem, sensoriamento remoto e assimilação de dados.

A assimilação de dados, por sua vez, consiste da combinação de dados observacionais com modelos de PNT, representando a atmosfera de maneira mais completa e realista, melhorando a condição inicial dos modelos e a acurácia da previsão. A partir deste tipo de inserção de dados e ajustes em modelos regionais é possível aumentar a confiabilidade nas previsões e assim melhorar a previsão de eventos extremos.

Estudos recentes nesta área mostram que a assimilação de dados de radares em modelos de PNT pode trazer melhorias significativas na previsão do tempo de curto prazo (Craig et al. (2012); Sokol, 2011; Vendrasco et al. (2016); Xiao e Sun, 2007). Os radares meteorológicos são importantes ferramentas para as previsões de curtíssimo prazo e o monitoramento do tempo. Através deles é possível estimar taxas de precipitação para lugares onde não há cobertura total de pluviômetros em superfície, e é possível analisar o deslocamento e o ciclo de vida do sistema atuante em sua área de cobertura.

Por outro lado, a inclusão de dados de radares meteorológicos nos modelos de previsão é uma área de estudo recente e ainda não possui muitas aplicações em centros operacionais. No Brasil, por exemplo, a disponibilidade desses dados só se tornou representativo a partir de 2011, com um aumento da rede de radares brasileira. A partir disso, tornou-se possível o estudo de assimilação de dados de radar para as áreas nas quais os sistemas convectivos de mesoescala apresentam uma atuação mais significativa, buscando obter melhores resoluções nos modelos e representar satisfatoriamente os SCMs.

Uma das regiões preferenciais de ocorrência dos SCM na América do Sul é a bacia do rio Paraná, onde estes sistemas se formam rapidamente e podem perdurar por várias horas (Velasco e Fritsch, 1987). A região oeste do Paraná possui importantes linhas de transmissão de energia e também abriga a bacia do rio Paraná. Nesta área é localizada uma das maiores usinas geradoras de energia hidrelétrica de todo o mundo: a Usina Hidrelétrica de Itaipu. Essa rede de reservatórios é afetada por diversos sistemas meteorológicos, em especial os SCMs, tanto de maneira imediata com grande precipitação em curtos períodos, quanto na contribuição na precipitação acumulada nos meses de estação chuvosa. Por isso, é necessário um sistema eficaz de monitoramento e previsão destes sistemas juntamente com a melhoria do conhecimento desses fenômenos, para mitigar os efeitos destes eventos severos que atingem a região do estado do Paraná e Paraguai.

Esse trabalho faz uma análise da aplicação da assimilação de dados de radar na previsão de sistemas convectivos de mesoescala, utilizando dados de radares no Sul do Brasil e Paraguai. Ao realizar simulações com assimilação de dados desses radares para o caso selecionado de SCM, são abordadas as vantagens e as limitações do uso de assimilação de dados. Essas análises buscam melhorar o entendimento da evolução dos SCMs e da previsão do tempo relacionada a eventos severos na região de estudo. Além disso, o uso indireto de dados de umidade e velocidade dos hidrometeoros presentes na atmosfera pode resultar em uma melhoria na previsão do posicionamento de núcleos convectivos e na precisão da localização da precipitação além de fornecer resultados com significativa melhora para centros operacionais de previsão do tempo, principalmente no curto e curtíssimo prazo.

Veber e Rocha (2016) analisaram resultados do modelo Weather Research and Forecasting (WRF) utilizado pelo CPTEC/INPE para as Olimpíadas do Rio de Janeiro em 2016 com resolução horizontal de $1 \mathrm{~km}$. Os autores verificaram que o modelo teve boa destreza na previsão de rajadas de vento superiores a $40 \mathrm{~km} / \mathrm{h}$, tanto em situações relacionadas com sistemas meteorológicos de escala sinótica, quanto em eventos associados a fenômenos de menor escala, como as brisas locais. A destreza das previsões do WRF mostrada em diversos trabalhos pode obter resultados de melhor qualidade quando se inclui o procedimento de assimilação de dados.

Assim, este trabalho mostra a importância da assimilação de dados de radar realizada de maneira indireta e suas aplicações para SCMs. Em síntese, este trabalho consiste em avaliar o impacto da assimilação de dados dos radares de Assunção-Paraguai, Cascavel-PR fazendo uso do modelo WRF, verificando a previsão da precipitação associada aos SCMs com previsões de $6 \mathrm{~h}$, para rodadas com e sem inicialização prévia.

Dessa maneira, na seção 2 são mostrados a área de estudo e dados utilizados, bem como configuração do modelo e modo como foi realizada a assimilação de dados. Na seção 3 são mostrados os resultados da assimilação, previsão de precipitação e análise do SCM selecionado. As conclusões e sugestões de trabalhos futuros são mostradas na seção 4 .

\section{Materiais e Métodos}

Os dados utilizados para presente trabalho compreendem o período de dois dias antes da formação do SCM até sua dissipação. Devido ao alto custo computacional necessário para a realização dos experimentos, foi selecionado apenas um caso de SCM ocorrido entre os dias 6 e 8 de novembro de 2014. O caso selecionado não pôde ser classificado como linha de instabilidade (LI) ou Complexo Convectivo de Mesoescala (CCM) - a duração, excentricidade, área e temperatura de brilho não atendem aos critérios de classificação de CCM de Maddox, (1980) - embora tenham apresentado altos acumulados de precipitação.

Os dados de análise meteorológica são provenientes do modelo Global Forecast System (GFS) do National Centers for Environmental Prediction (NCEP) e têm resolução espacial de $0.5^{\circ}$ de longitude e latitude. Estes dados forneceram condições iniciais e de contorno para a grade do 
WRF data assimilation system (WRFDA), na qual os dados de radar foram assimilados.

Os dados observacionais que foram assimilados compreendem medições de superfície e de altos níveis. Os dados de superfície, tais como SYNOP, METAR, dados de boias oceânicas e outros, são provenientes do GTS (Global Telecommunications System), contendo variáveis meteorológicas como pressão de superfície, temperatura do ar, temperatura do ponto de orvalho, direção e velocidade do vento. Os dados de altos níveis são de radiossondas e medições em aeronaves provenientes do GTS. As variáveis contidas nestes dados são as mesmas que são utilizadas em superfície, mas em diversos níveis da atmosfera. Estes dados foram assimilados a cada $6 \mathrm{~h}$.

Embora a distribuição de estações de radiossondagem no Brasil seja esparsa, na área de ocorrência dos SCMs do sistema foram selecionadas duas estações como representativas das condições atmosféricas em altitude durante $o$ caso, para a comparação pontual do perfil vertical do modelo com e sem assimilação. As estações selecionadas para essa comparação foram Curitiba (latitude 2531'42” S, longitude $49^{\circ} 10^{\prime} 32^{\prime \prime}$ W) e Assunção no Paraguai (latitude:

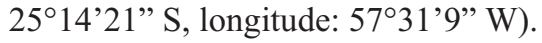

Os radares incluídos no procedimento de assimilação são os radares Doppler do Sistema Meteorológico do Paraná (SIMEPAR) e da Dirección Nacional de Aeronautica Civil (DINAC). O radar do SIMEPAR está situado em Cascavel (Latitude: $24.87^{\circ} \mathrm{S}$, longitude: $53.52^{\circ} \mathrm{W}$, altitude: $719.8 \mathrm{~m}$ ). Este radar possui abertura de feixe de $1.0^{\circ} \mathrm{e}$ 15 elevações, com dados no raio de 240 ou $480 \mathrm{~km}$, resolução de $125 \mathrm{~m}$, banda S e largura de pulso de 0.8 e $2.0 \mu$ s. O radar da DINAC está localizado em Assunção, no Paraguai (Latitude: $25.33^{\circ} \mathrm{S}$, longitude: $57.52^{\circ} \mathrm{W}$, altitude: $118.0 \mathrm{~m}$ ) e tem comprimento de onda de $5.4 \mathrm{~cm}$ (banda $\mathrm{C}$ ), 11 elevações, e com resolução de $250 \mathrm{~m}$, raio de cobertura dos dados de $250 \mathrm{~km}$ e largura de pulso de $0.8 \mu \mathrm{s}$.

A distribuição espacial dos radares e a área de cobertura de seus dados dentro da grade utilizada para as rodadas do modelo são mostradas na Fig. 1, bem como as áreas de intersecção dos radares. O relevo pode indicar problemas relacionados a ecos e pontos persistentes de refletividade.

Os dados foram disponibilizados pelo SIMEPAR em formatos volumétricos. A varredura volumétrica do radar é um dado bruto composto por varreduras em elevações fixas e azimute variando.

\section{AREA DE ESTUDO}

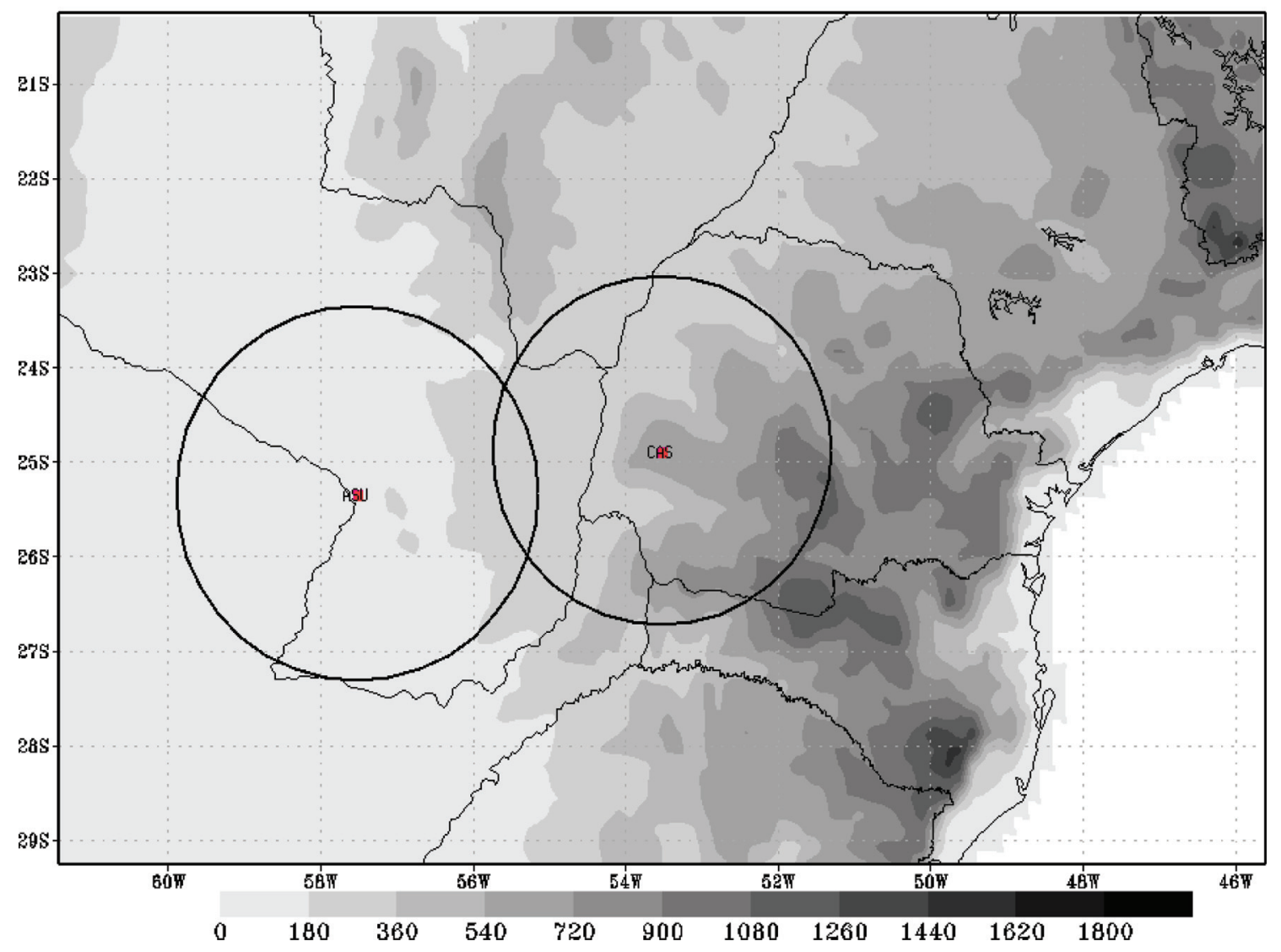

Figura 1 - Posição dos Radares de Assunção (ASU), Cascavel (CAS) e suas respectivas áreas de cobertura e relevo da região em metros (em tons de cinza). A área mostrada compreende a grade do modelo regional WRF. 
O PPI (Plan Position Indicator) foi gerado a partir da interpolação dos dados brutos do radar (originalmente em coordenadas polares) para uma grade cartesiana regular de espaçamento de $500 \mathrm{~m}$. Lembrando que o PPI é a varredura original do radar, com 360 azimutes (1 a cada grau) e um ponto de observação a cada para $125 \mathrm{~m}$ (Cascavel) e $250 \mathrm{~m}$ (Assunção) de distância radial do radar, por azimute. O radar de Cascavel (CAS) possui tratamento de dados que elimina ruídos como os ecos de terreno, e de Assunção (ASU) não possui tratamento dos ruídos. Com o intuito de fornecer ao modelo um dado em alta resolução para a assimilação, foram gerados PPIs com resolução de 500 m para os dois radares.

Assim, são gerados os PPIs e calculados os erros associados a cada dado do radar, para compor a matriz de covariância dos erros de observação. O erro em cada ponto é calculado com base no desvio padrão dos dados em torno do ponto de interesse. Os dados foram preparados apenas para varreduras em horas exatas ou da varredura realizada nos minutos próximos a hora cheia. Não há interpolação dos PPIs para a grade do modelo, tendo em vista que há maior detalhamento nos dados de $500 \mathrm{~m}$. Com isso, os dados são assimilados na resolução com a qual o PPI foi gerado.

\subsection{Modelagem e assimilação de dados}

A modelagem da atmosfera foi realizada utilizando resolução vertical de 45 níveis, com topo em $50 \mathrm{hPa}$. A área de estudo compreende 800 pontos de longitude e 500 de latitude, área mostrada na Fig. 1. O sistema foi integrado para uma grade, com resolução horizontal de $2 \mathrm{~km}$ x $2 \mathrm{~km}$, com centro na localização do radar de CAS. Para a assimilação de dados, usando o WRFDA as configurações de parametrizações, área e a resolução foram mantidas em relação à rodada sem assimilação do WRF. A versão utilizada foi a 3.4 modo- ARW (Advanced Reseach WRF). Nessa versão foi possível realizar a assimilação indireta dos dados de radar, e informações complementares podem ser encontradas em Skamarock et al. (2008).

Para o presente estudo, no modelo WRF foram utilizados como configuração dos processos físicos o esquema de radiação de onda longa RRTM (Rapid Radiative Transfer Model), e para radiação de ondas curtas o esquema de Dudhia (1989). A parametrização de microfísica utilizada foi a WDM6 (WRF Momento Duplo e esquema de 6 classes de hidrometeoros). Para esse tipo de microfísica, além da previsão para seis classes de hidrometeoros, há também a variável prognóstica do número de concentração de núcleos de condensação de nuvem para processos quentes (Lim e Hong, 2010). A microfísica que possui momento duplo permite uma maior flexibilidade da distribuição de tamanho e é um dos métodos promissores para melhorar o processo microfísico na área de modelagem de mesoescala. Essa parametrização é adequada para modelos de alta resolução (Hong e Lim, 2009). A coordenada vertical usada é a sigma - coordenada de pressão hidrostática que acompanha o terreno.

Para a assimilação de dados, foi necessário gerar a matriz de covariância dos erros de background. Essa matriz fornece um indício da confiabilidade dos dados do modelo em relação aos dados observados. A partir dela é possível atribuir pesos ao modelo quando este estiver diferente do que foi observado (do dado que foi assimilado). Essa matriz foi calculada pelo método do NMC (National Meteorological Center - antigo nome dado ao NCEP). Esse método consiste nos cálculos de erros entre previsões iniciadas em horários distintos e grande parte dos centros meteorológicos utiliza este método para estimar a covariância do erro de previsão (Parrish e Derber, 1992). Com base nisso, foram realizadas previsões de $24 \mathrm{~h}$ iniciadas as $00 \mathrm{Z}$ e $12 \mathrm{Z}$ para todos os dias dos meses de outubro a dezembro de 2014. São comparadas as diferenças entre as duas previsões iniciadas em tempos distintos, porém válidas para o mesmo horário UTC. O método baseia-se no princípio de que as previsões estão corretas e que previsões para um mesmo horário iniciadas em horários diferentes devem ser iguais. O período de 3 meses utilizado é suficiente para os estudos de caso nesse período, porém para a utilização operacional é sugerido que a matriz seja composta por previsões de um ano inteiro, a fim de captar as variações sazonais dos erros do modelo.

Os dados dos radares foram assimilados pelo sistema de assimilação de dados do WRFDA, como utilizado por Vendrasco et al. (2016), que consistiu em utilizar a equação de assimilação indireta de Wang et al. (2013) para transformar a refletividade $(Z)$ em razão de mistura de água de chuva (qr) e a assimilação de dados de vento radial. Os trabalhos dos autores supramencionados mostraram que a assimilação direta de refletividade apresenta limitações que são amenizadas fazendo uso da assimilação indireta desta variável, ou seja, realizando a conversão de refletividade para razão de mistura de água de chuva antes do processo de assimilação. As equações e ajustes utilizados para a assimilação podem ser encontrados em Vendrasco et al. (2016).

A frequência de assimilação dos dados depende do ciclo utilizado. Após testes que são mostrados nos resultados, a avaliação objetiva estatística indicou a necessidade da inicialização prévia do modelo, ou warm-start, e partir deste teste, todas as rodadas foram realizadas com inicialização prévia. O período de ciclos que compreende a inicialização do modelo é chamado de spinup inicial, com 10 ciclos de $6 \mathrm{~h}$, definido como o tempo que o modelo leva para se estabilizar e gerar melhores resultados.

A assimilação de dados do GTS, com dez ciclos, na fase de spin up a cada 6 h, é mostrada na Fig. 2.a e 2.b. Depois é realizado um ciclo intermediário de $3 \mathrm{~h}$, de modo a gerar o arquivo necessário para que o radar seja assimilado pelo período de $3 \mathrm{~h}$, de hora em hora (Fig. 2.c). O esquema 


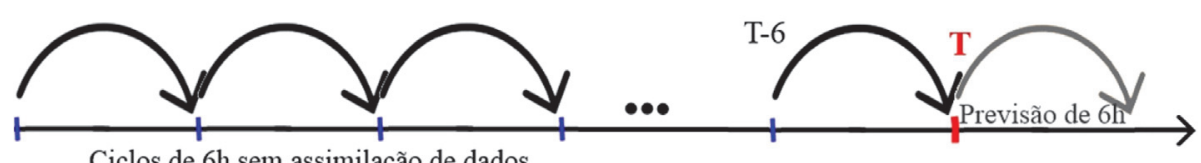

Ciclos de $6 \mathrm{~h}$ sem assimilação de dados

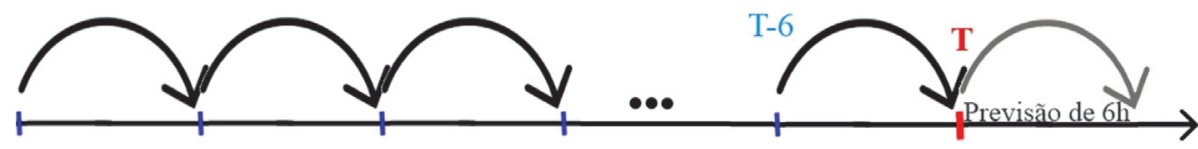

Ciclos de 6 h com assimilação do GTS

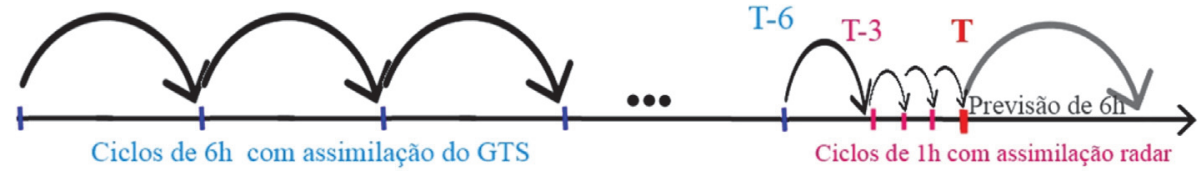

Figura 2 - Inicialização do modelo ilustrada com ciclos com e sem assimilação de dados para uma previsão de $6 \mathrm{~h}$. Em a) Onze ciclos de $06 \mathrm{~h}$ sem nenhum tipo de assimilação, b) Onze ciclos de $6 \mathrm{~h}$ com a assimilação de dados convencionais do GTS, c) Dez ciclos de $6 \mathrm{~h}$ com assimilação de dados de GTS e três ciclos de assimilação de dados de radar de $1 \mathrm{~h}$. A partir do tempo $T=0$ é realizada uma previsão de $6 \mathrm{~h}$.

de assimilação de radar usado é baseado na assimilação de quatro dados horários de radar.

A partir da assimilação de dados de superfície e altos níveis, é possível verificar qual a real contribuição da assimilação dos dados de radar quando comparada a assimilação dos demais dados disponíveis (Fig. 2.c).

\subsection{Avaliação estatística das previsões numéricas}

Para quantificar a acurácia do modelo ao prever a precipitação, é necessário aplicar uma analise objetiva nos resultados. A avaliação da previsão de precipitação de maneira objetiva foi realizada utilizando o índice FSS (Fractions Skill Score). Esse índice fornece a fração de acerto do modelo dentro de um limiar de precipitação e um raio de cobertura especificado. Pode ser calculado pela equação:

$$
F S S=1-\frac{1}{N} \frac{\sum_{1}^{N}\left(P_{f}-P_{o}\right)^{2}}{\sum_{1}^{N} P_{f}^{2}+\sum_{1}^{N} P_{o}^{2}}
$$

na qual $P_{f}$ é a fração prevista, $P_{o}$ é a fração observada, $N$ é o número de janelas que a área foi dividida. Esse é um índice usado para avaliar a precipitação acumulada por sistemas convectivos em modelos de alta resolução (Roberts e Lean, 2008). O FSS possui limitações ao detectar os aspectos da precipitação. Sua principal utilidade é mostrar a relação da acurácia do posicionamento dos núcleos convectivos na previsão de precipitação. Seu valor varia de 0 a 1 , indicando que quanto mais próximo a 1 , melhor foi o posicionamento da previsão de precipitação em relação ao campo de precipitação observada. Por se tratar se um sistema convectivo, com precipitações mais intensas, foi selecionado para o cálculo do FSS os limiares de $5 \mathrm{~mm}$ de precipitação em um raio de $10 \mathrm{~km}$.
De maneira complementar, assim como utilizado por Vendrasco et al. (2016), é aplicado o LRMSE (Local Root Mean Square Error) que indica a magnitude do erro nos valores de precipitação previstos. É definido pela fórmula:

$$
\text { LRMSE }=\sqrt{\frac{1}{N} \sum_{1}^{N}(\bar{M}-\bar{O})^{2}}
$$

onde $N$ é o número total de pontos de grade do domínio verificado, $\bar{M}$ e $\bar{O}$ são respectivamente as médias de precipitação prevista pelo modelo e observada nos pontos dentro do raio usado para o cálculo do FSS.

Assim, aplicando os dois índices em conjunto é possível estimar qual configuração de assimilação obteve melhor desempenho em prever a localização e os valores da precipitação acumulada para cada rodada do modelo.

\section{Resultados e Discussão}

Os resultados foram divididos em etapas e primeiramente são mostradas as condições atmosféricas de mesoescala, seguida da análise remota da fase intensa do sistema com imagens de satélite e radar. Após a descrição do evento, há comparações de perfis verticais, previsão de precipitação e a avaliação estatística do desempenho das previsões.

\subsection{Descrição do evento}

O SCM analisado começou a se formar por volta das $12 \mathrm{Z}$ do dia 06/11/2014 ao norte do RS e SC, onde se intensificou ganhando extensão vertical e horizontal em direção ao oceano e estado do PR (Figura não mostrada). Entre os horários das 6 e $12 \mathrm{Z}$ do dia $07 / 11$ o sistema teve sua fase mais ativa, com temperaturas de brilho no topo das nuvens que atingiram valores inferiores a $-80^{\circ} \mathrm{C}$. Baixos valores de temperaturas de brilho como os observados neste caso indicam alta probabilidade de ocorrência de tempestades severas com descargas elétricas e possivel- 
mente granizo em SCMs, de acordo com Machado et al. (1998).

Nas imagens da Divisão de Satélites e Sistemas Ambientais (DSA/CPTEC) captadas pelo satélite GOES no canal infravermelho com temperatura de brilho realçada (Figs. 3.a e 3.b) para os horários de intensa precipitação é possível ver a fase bastante ativa do sistema. Após às $18 \mathrm{Z}$ do dia 07/11 (Fig. 3.b) o SCM teve diminuição em sua área e indicou sinais de dissipação e propagando para nordeste da área de estudo. As imagens dos radares das $12 \mathrm{Z}$ de Assunção e Cascavel (Figs. 3.c-3.d respectivamente) e das $18 \mathrm{Z}$ do dia 07/11 (Figs. 3.e-3.f) mostram altos valores de refletividade para a segunda elevação dos radares.

A análise da parte termodinâmica do SCM precisa ser realizada comparando dados observados com os resultados do modelo, a fim de conhecer os erros e limitações associadas a esta ferramenta. As saídas do modelo descritas na seção 2 são aqui comparadas.

A comparação das sondagens de $12 \mathrm{Z}$ do dia 07/11/2014 para Curitiba (Fig. 4.a) e Assunção (Fig. 4.b) mostra que o perfil da diferença de Assimilação de Dados de Radar (ADR) teve melhor representatividade do que as outras análises (sem Assimilação e com GTS). Os resultados com ADR apresentam seus melhores resultados entre os níveis de 750 a $400 \mathrm{hPa}$. A ADR manteve-se mais próxima a linha tracejada do zero, onde a análise é igual a observação, ou o mais próximo do estado real da atmosfera naquele perfil de umidade (razão de mistura de vapor).

\subsection{Previsão de precipitação}

A previsão de seis horas de precipitação acumulada foi realizada para as três diferentes condições iniciais, comparadas e validadas espacialmente com as estimativas de precipitação combinadas com estações de superfície - utilizando o produto CoSch3 (Combined Scheme $3 h$; Ferreira et al. (2015)). O CoSch3 é a combinação entre a estimativa de precipitação de $3 \mathrm{~h}$ do produto $3 \mathrm{~B} 42$ Real Time do TMPA (Tropical Rainfall Measuring Mission Multisatellite Precipitation Analysis) com dados de precipitação acumulada em $3 \mathrm{~h}$ de todas as estações telemétricas de superfície disponíveis na região do estudo. Esse produto foi desenvolvido baseado na metodologia de Vila et al. (2009) e validado para alta resolução temporal e espacial e obteve resultados superiores às estimativas de precipitação sem

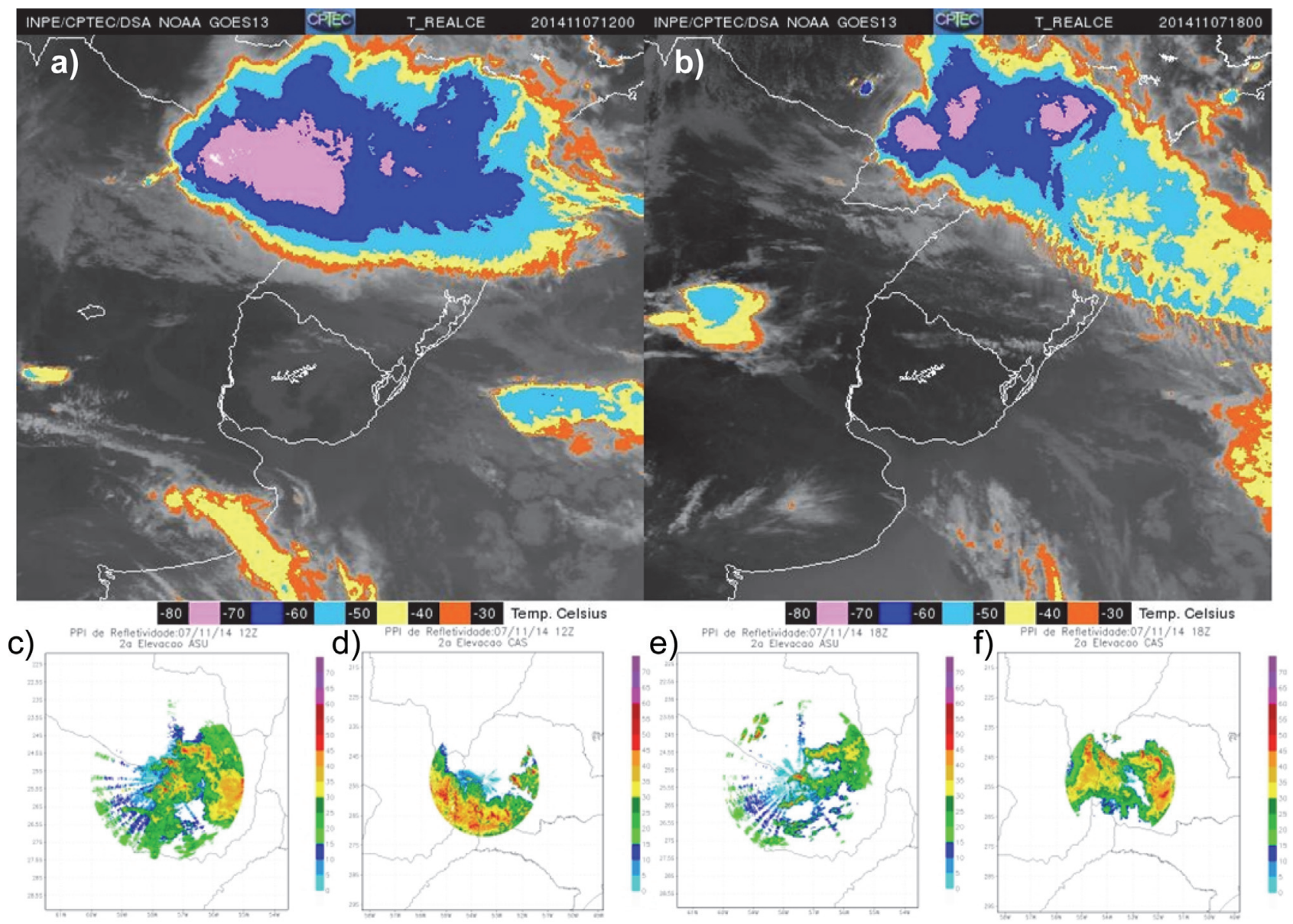

Figura 3 - Imagens de temperatura de brilho realçada do satélite GOES13 da DSA/CPTEC para as 12 e 18 Z do dia 07/11/2014 (a,b, respectivamente) e abaixo as imagens de refletividade da segunda elevação dos dois radares que tiveram seus dados assimilados nos horários 12 e 18 Z: Assunção (c, e) e Cascavel (d, f) respectivamente. 
(a)

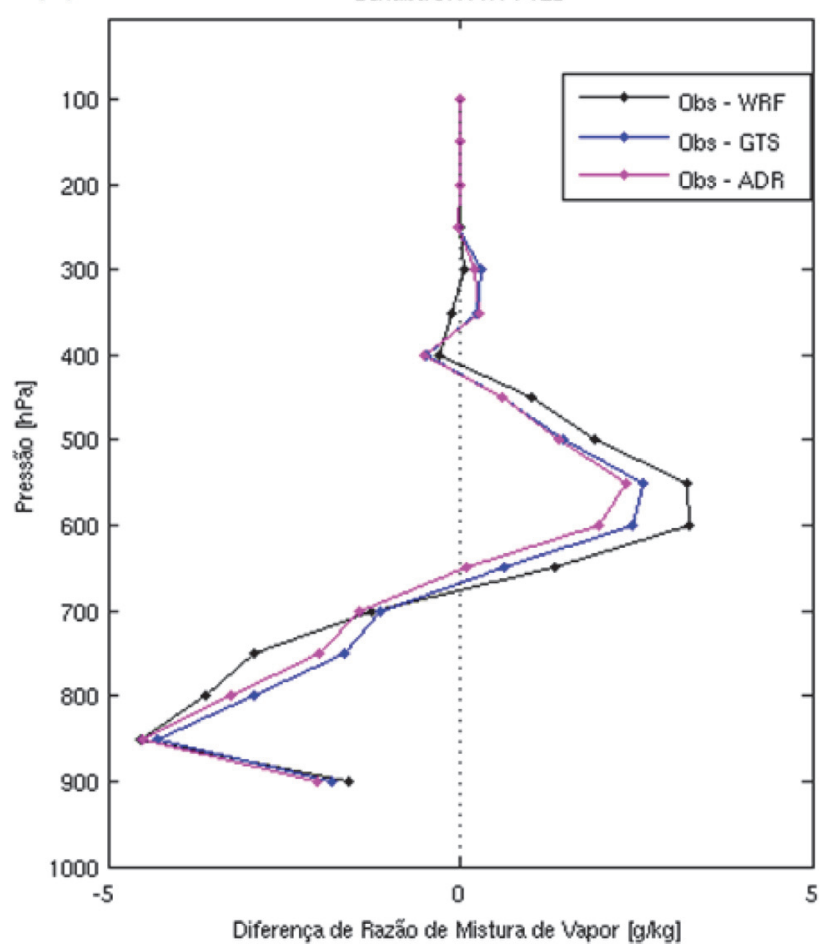

(b)

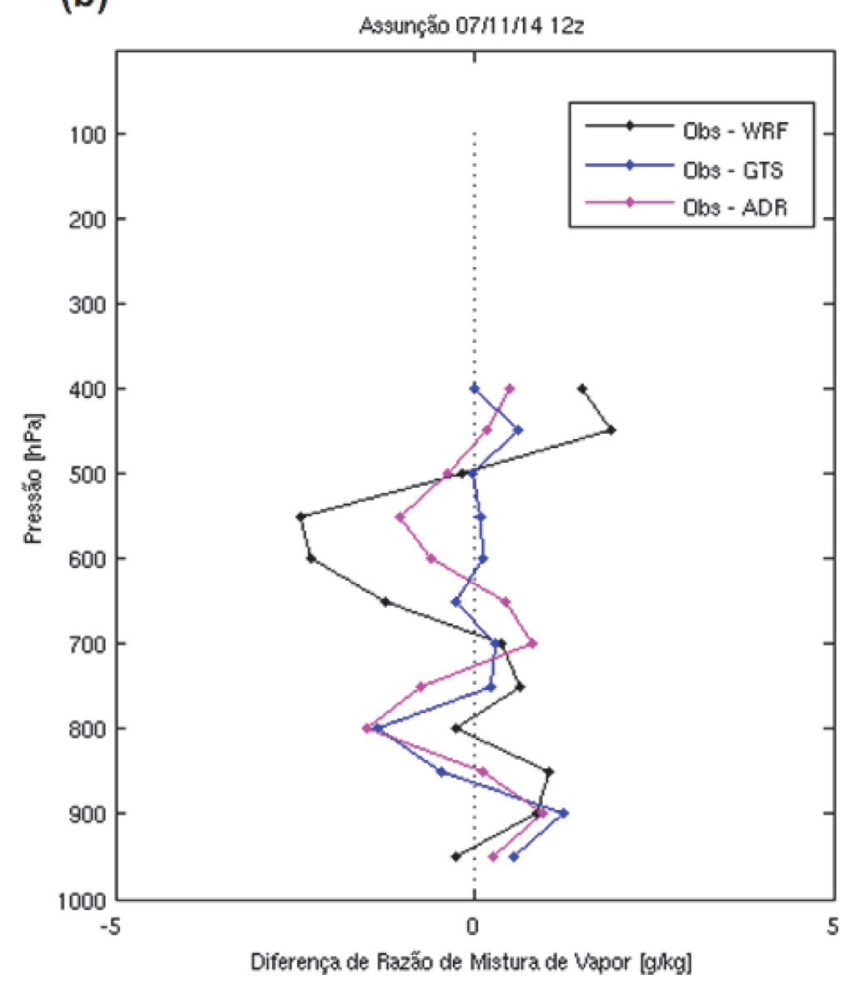

Figura 4 - Comparação da diferença (subtração) entre sondagem de Razão de Mistura de Vapor com as análises usadas para a previsão durante a formação do SCM dia 07/11/2014 as 12 Z, para (a) Curitiba e (b)Assunção. Observado e o modelo sem assimilação (Obs -WRF) em linhas pretas, entre o observado e o perfil de temperatura gerado a partir da assimilação apenas do GTS (Obs - GTS) em azul, e diferença entre observado e o perfil da análise gerada com a assimilação de dados de radar (Obs - ADR) em rosa.

correção. Para a comparação com as previsões de $6 \mathrm{~h}$, foram somadas as precipitações acumuladas correspondentes ao horário da previsão. Mais informações e validações do produto podem ser encontradas em Ferreira (2016) e Ferreira et al. (2016).

Foram realizados diversos testes, e alguns deles são mostrados na Fig. 5. O horário definido para essa comparação é da fase madura do SCM com altas taxas de precipitação, entre 12 e $18 \mathrm{Z}$ do dia 07 de novembro de 2014. Foram realizadas rodadas com inicialização fria, ou seja, sem ciclos de assimilação de dados, e considerando apenas a condição inicial e de fronteira do GFS. Os resultados obtidos no posicionamento da precipitação para um horário de grande acumulado de precipitação é mostrado e comparado ao GFS (Fig. 5.b), que indica a precipitação em uma área visualmente diferente (quantitativamente e em posição) da a estimativa de precipitação de satélite (produto TMPA 3B42RT) combinada com dados de precipitação de estações telemétricas no estado do Paraná - ou também campo de precipitação do CoSch3 (Fig. 5.a).

Nesta comparação, observa-se o deslocamento da precipitação para o estado de Santa Catarina e norte do Rio Grande do Sul, porém se não há ciclos, esse erro da escala global é inserido no modelo de mesoescala a partir do uso do modelo GFS como condição inicial e de fronteira. Comparando a previsão do WRF (Fig. 5.d - WRF cold start) que fez uso da condição inicial do GFS como o próprio modelo global GFS, é possível dizer que não houve ganho entre utilizar um modelo de mesoescala com inicialização fria, já que a precipitação continua com os erros provenientes do modelo global. A partir dessa comparação surgiu a necessidade de realizar ciclos para analisar o ganho da inicialização prévia do modelo (warm start). As previsões de precipitação do WRF sem assimilação com e sem inicialização prévia (Figs. 5.c-5.d, respectivamente) mostram grandes diferenças no campo de precipitação - principalmente posicionamento a noroeste do Rio Grande do Sul (RS) e Santa Catarina (SC) e também na intensidade dos valores. Essa alteração está relacionada à inicialização prévia, que também pode ser comparada através das análises dos valores do FSS na Tabela 1.

Quando os radares de ASU e CAS são assimilados (Figs. 5.e-f), eles forneceram um melhor posicionamento do sistema quando comparado à estimativa de satélite (Fig. 5.a), melhorando a localização dos núcleos mais intensos de precipitação. Entretanto, assimilar os dados de radar não retirou parte da precipitação com localização errada - no estado de SC (Fig. 5.f). Isso pode ser justificado pelo fato da assimilação do dado de radar gerar modificações representativas restritas a área do raio de cobertura de dados do radar e não conseguir corrigir o posicionamento errôneo proveniente do modelo global (precipitação deslo- 
a)

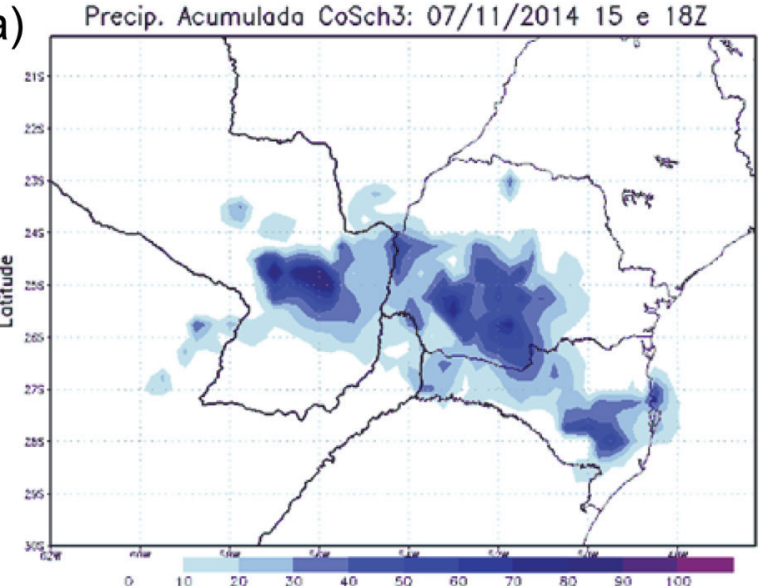

c)

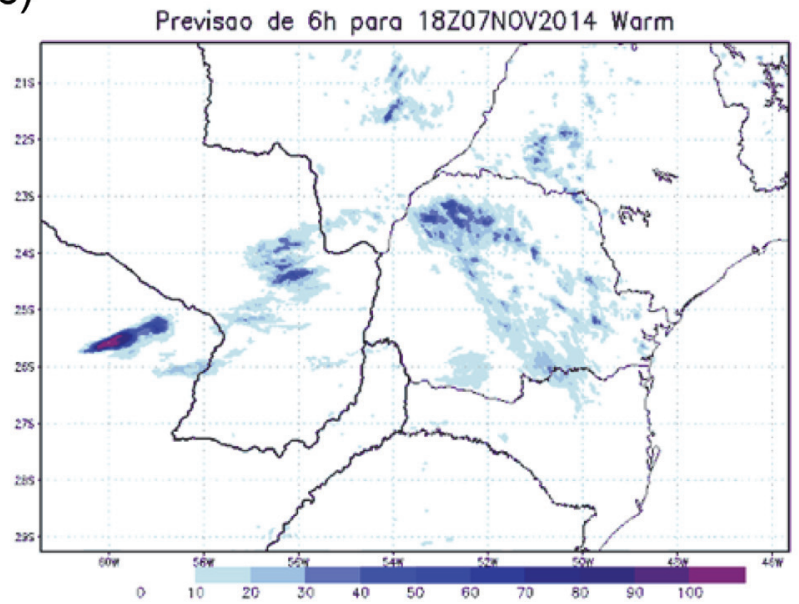

e)

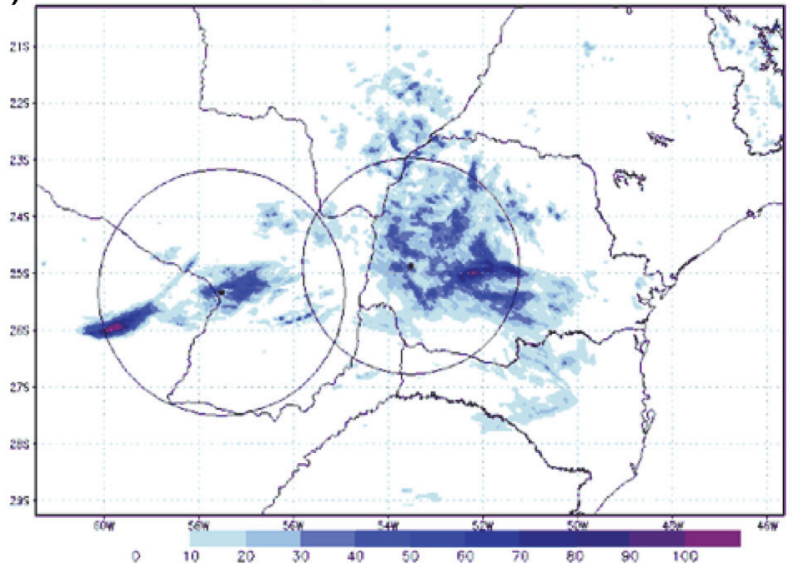

b)

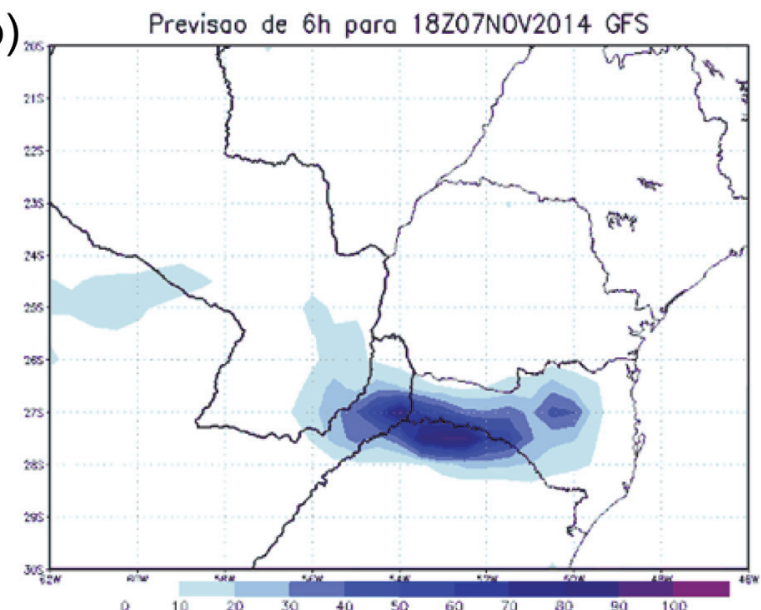

d)

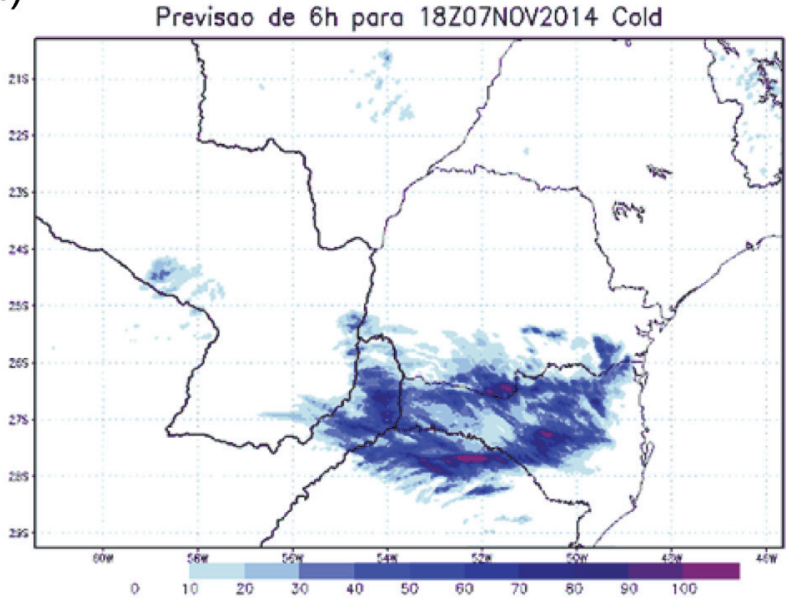

f)

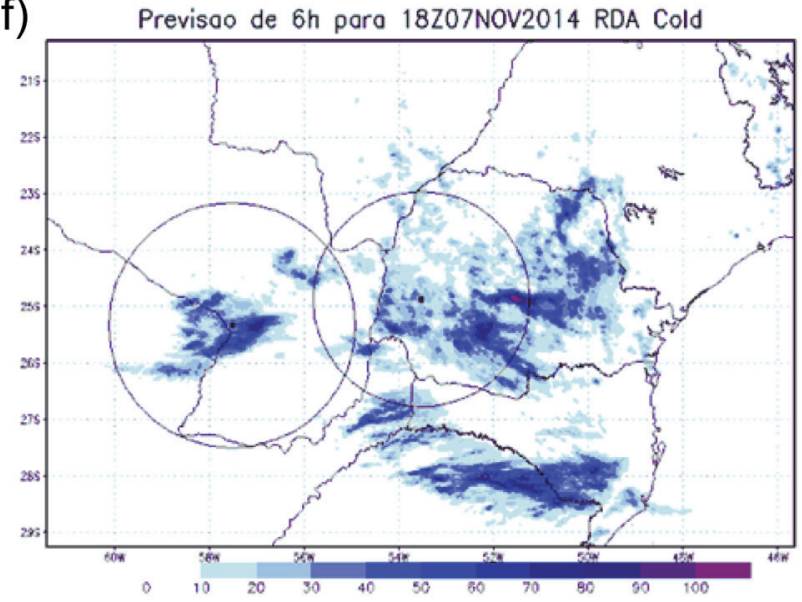

Figura 5 - Comparativos da previsão de precipitação acumulada em 6 h entre 12 e 18 Z do dia 07/11/2014. A estimativa pelo CoSch em (a), previsão do GFS (b), previsão do WRF sem assimilação de dados com inicialização quente (c) e com inicialização fria (d), e previsões a partir do WRFDA com assimilação dos dados de Assunção e Cascavel com inicialização quente (e) e com inicialização fria (f).

cada próxima ao noroeste do RS, observada em todos os casos que modelo é rodado sem ciclos, isto é, sem inicialização prévia - Figs. 5.b-d-f). Isso mostra a necessidade de uma cobertura maior de dados de radar.

A Tabela 1 mostra a avaliação estatística que indica a melhoria ao se usar warm start comparando os valores com e sem assimilação. O maior valor possível para o FSS é 1, indicando que o modelo conseguiu prever corretamente o posicionamento do sistema de acordo com o limiar de precipitação e raio de análise (5 mm em $10 \mathrm{~km})$. Quanto mais próximo a zero, menor o sucesso do modelo ao prever a precipitação. O menor valor do FSS e o maior valor de 
Tabela 1 - Cálculo estatístico para as rodadas com inicialização quente e fria e com e sem assimilação de dados para o período $12-18 \mathrm{Z}$ do dia 07/11/2014, para o limiar de $5 \mathrm{~mm}$ no raio de $10 \mathrm{~km}$. Quanto mais próximo de 1 o valor do FSS maior o sucesso ao detectar o limiar de precipitação no raio definido.

\begin{tabular}{|c|c|c|}
\hline & FSS & LRMSE (mm) \\
\hline WRF sem assimilação e cold start & 0,111 & 13,020 \\
\hline $\begin{array}{l}\text { WRFDA com assimilação de Radar e } \\
\text { cold start }\end{array}$ & 0,618 & 12,208 \\
\hline WRF sem assimilação e warm start & 0,487 & 12,255 \\
\hline $\begin{array}{l}\text { WRFDA com assimilação de Radar e } \\
\text { warm start }\end{array}$ & 0,624 & 10,774 \\
\hline
\end{tabular}

erro (LRMSE) foram encontrados na rodada do WRF sem assimilação e com cold start. O maior valor do FSS foi encontrado na rodada do WRFDA com assimilação de radar e warm start. Essa rodada apresentou o menor erro quando compardos os valores do LRMSE.

A partir da rodada com inicialização quente (warm start) sem assimilação de dados (Fig. 5.c), notou-se uma grande modificação no campo de precipitação, inclusive reduzindo os valores relativamente altos que estavam sendo previstos. Com isso, é possível observar que quando os ciclos são realizados, estes podem obter uma previsão de precipitação mais realista e superior quando comparados à inicialização fria, mostrando assim a importância do spinup inicial para que o modelo se estabilize e não produza precipitações não realísticas concordando com Warner (2011). Essas rodadas foram realizadas como teste, para a fase intensa do sistema, para justificar e mostrar a importância da inicialização do modelo com spinup e foram confirmadas pelos índices estatísticos mostrados na Tabela 1 .

A previsão da precipitação acumulada é analisada para o caso selecionado, de acordo com a evolução e propagação do sistema para as rodadas realizadas. Na Fig. 6 é comparada uma previsão das 12 as $18 \mathrm{Z}$ do dia 06 de novembro de 2014, representando a formação inicial do SCM. O modelo sem assimilação (Fig. 6.b) subestima bastante os valores e não captou muito bem a área de precipitação, e a assimilação de dados do GTS (Fig. 6.d) não apresentou diferenças significativas. A rodada de previsão com a análise gerada pela ADR indica um núcleo intenso de precipitação na área de intersecção dos radares. A partir da análise da Fig. 6, nota-se que nenhuma das três configurações para a previsão de $6 \mathrm{~h}$ obtiveram resultados satisfatórios, porém, a $\mathrm{ADR}$ (Fig. 6.c) foi a única capaz de
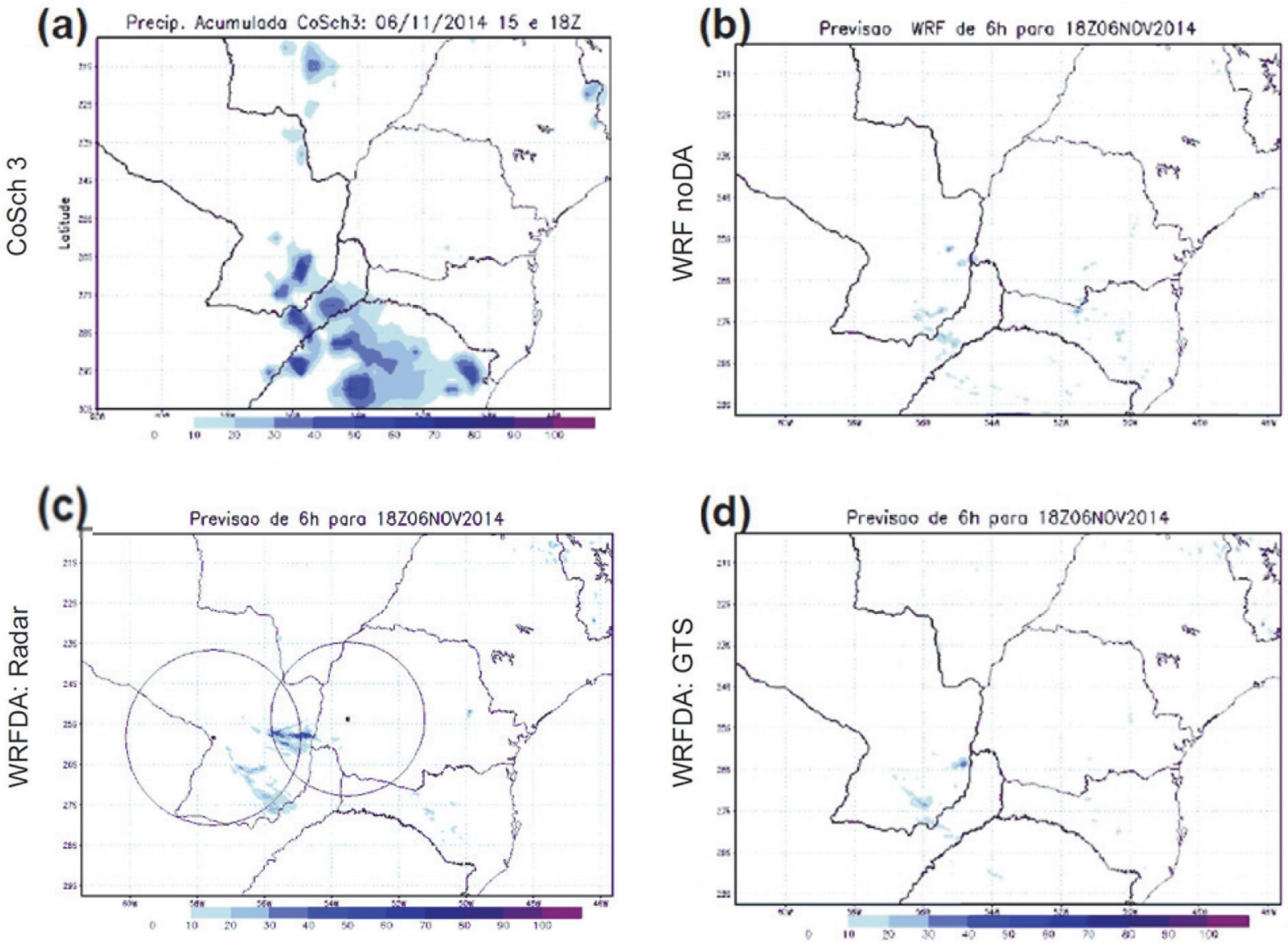

Figura 6 - Precipitação acumulada de $12 Z$ a 18 Z de 06/11/2014: (a) Estimativa do CoSch3, previsões de 6 h do (b) WRF sem assimilação, (c) WRFDA com assimilação de dados de radar e GTS e (d) WRFDA com assimilação de GTS. 
detectar um núcleo de precipitação do sudeste do Paraguai e se aproximar mais dos resultados estimados (Fig 6.a).

O SCM, que já está em sua fase madura, propaga-se para a área de cobertura dos radares no horário de 12 a $18 \mathrm{Z}$. A previsão para esse horário bastante intenso está na Fig. 7. A previsão sem assimilação (Fig. 7.b) subestimou bastante os valores de precipitação e também não teve boa relação espacial no Paraná, mostrando-se aparentemente deslocada. A rodada do GTS teve os valores muito subestimados (Fig. 7.d), entretanto teve boa relação espacial com o observado. A rodada com ADR (Fig. 7.c), embora superestimada teve uma boa relação com a distribuição espacial da precipitação indicando vários pequenos núcleos de precipitação no oeste do Paraná e região central do Paraguai.

A avaliação objetiva do modelo fornece um dado quantitativo sobre o impacto da assimilação de dados no estudo dos SCM e demais sistemas. Logo na primeira rodada, todas os resultados foram ruins (baixos valores de FSS) porém a Assimilação de Dados de Radar (ADR) ainda obteve um resultado levemente superior (Fig. 8.a). Nas demais rodadas, a Assimilação de dados do GTS (AGTS) obteve um bom resultado e em geral acima do WRF sem assimilação. $\mathrm{Na}$ fase bastante intensa do sistema, os valores das rodadas com assimilação de dados foram superiores a rodada sem assimilação de dados na análise. A assimilação
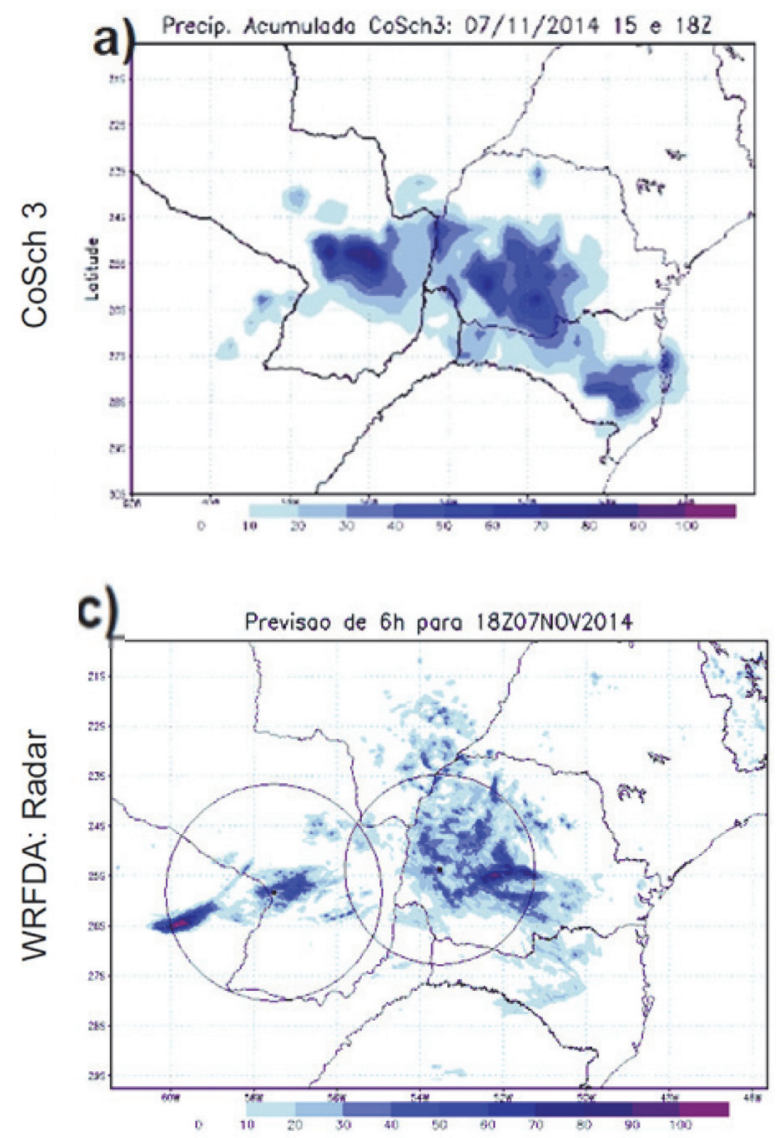

do GTS obteve resultados bastante semelhantes a ADR, porém na fase mais intensa da precipitação, o FSS da ADR teve maiores valores. O WRF sem assimilação obteve o pior desempenho em praticamente todas as rodadas. A partir desses valores, no geral, a ADR melhorou o posicionamento da previsão de $6 \mathrm{~h}$ de precipitação. $\mathrm{O}$ ganho ao assimilar os dados de radar, ou manteve-se igual ou superior ao modelo com assimilação de GTS, mostrando que ao assimilar o radar não há perda, embora algumas rodadas o ganho seja pequeno. Resultados similares foram encontrados por Vendrasco et al. (2016).

Para quantificar o quanto o modelo errou ao prever os valores da precipitação, o LRMSE foi calculado para todas as rodadas realizadas para o SCM com limiar de $5 \mathrm{~mm}$ em $10 \mathrm{~km}$, mostrado na Fig. 8.b. Na fase madura do sistema, a ADR possui o menor LRMSE e o maior erro é verificado no WRF sem assimilação (Fig. 8.b - linha preta). Na fase de dissipação as três rodadas tiveram erros similares.

A partir da análise objetiva com o FSS (Fig. 8.a) e o LRMSE foi possível comparar as três rodadas para a previsão de precipitação. É importante notar que quando o valor do FSS é baixo, as três configurações de rodada apresentam valores baixos. Isso mostra deficiências que podem estar relacionadas às três análises não terem representado bem a atmosfera. Também, podem estar relacio-
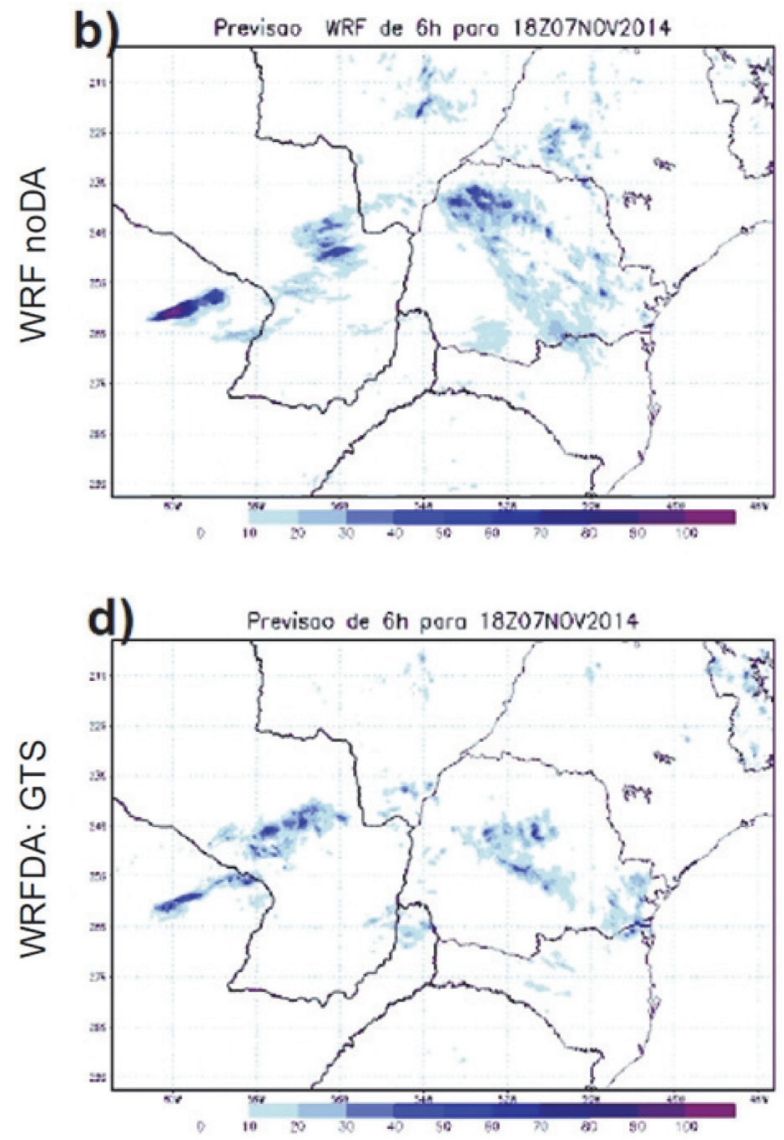

Figura 7 - Idem a Fig. 6 para o acumulado das 12 a 18 Z do dia 07/11/2014. 
(a)

Limiar de precipitacao $5 \mathrm{~mm}$ com Raio de $10 \mathrm{~km}$

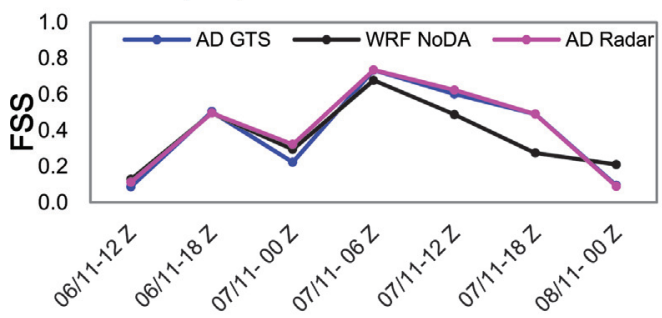

(b)

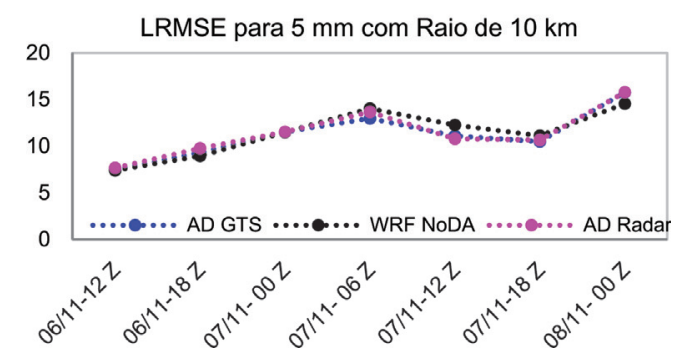

Figura 8 - Avaliação do índice FSS (a) e LRMSE (mm) (b) para todas as rodadas realizadas durante o SCM para o limiar de 5 mm de precipitação em um raio de $10 \mathrm{~km}$.

nadas a erros associados ao modelo avançar no tempo realizando a previsão, pois não há mais dados sendo assimilados e mesmo assim o resultado converge para baixa detecção de precipitação nos limiares comparados.

\section{Conclusões}

A análise do SCM e a avaliação do impacto da assimilação de dados dos radares foram realizadas utilizando o modelo WRF. A partir da assimilação de dados, foi possível realizar uma análise simplificada dos SCMs estudados utilizando resultados do modelo e dados de radar.

O estudo do SCM ocorrido em novembro de 2014 e a análise dos resultados das diversas configurações do modelo tem grande importância ao gerar conhecimento de quais são as limitações do WRF e da assimilação de dados de radar para a área de estudo. A partir da análise sinótica, os sistemas meteorológicos atuantes são identificados fornecendo indicativos das condições de tempo de grande escala nos próximos horários, e o diagnóstico de mesoescala também se torna importante na previsão de curto prazo. Aliados a modelagem atmosférica, é possível chegar a uma previsão mais eficiente, de modo que o meteorologista previsor possa identificar erros sistemáticos e persistentes em uma determinada região.

O trabalho consistiu no estudo do impacto da assimilação de dados no modelo WRF (dados de radar e dados convencionais) com diferentes configurações de rodada, comparando a fim de verificar o melhor desempenho dentre os experimentos realizados.

A assimilação de dados de radar, no geral, possui os melhores resultados quando são comparados os perfis de razão de mistura de vapor, fornecendo um bom indicativo do perfil atmosférico de umidade, diversas vezes melhor representado do que a assimilação apenas de dados convencionais. O modelo sem assimilação possui maiores erros em praticamente todos os casos e níveis, e possui desempenho ainda pior nos horários de grande atividade do SCM.

Na previsão de precipitação, a ADR posicionou melhor o sistema - em função da alteração no campo de razão de mistura integrada na vertical - quando comparada ao posicionamento do sistema na imagem de satélite e no posicionamento da precipitação.

Um dos principais resultados encontrados nesse trabalho consiste na importância da inicialização prévia do modelo, ou seja, a realização de ciclos para um spinup, independente se há ou não a assimilação de dados de radar. Com isso foi possível obter uma previsão de precipitação mais realista e superior do que as previsões com inicialização fria (que utilizam o modelo global como condição inicial), confirmando a importância do spinup inicial, com no mínimo dois dias (ou 10 ciclos de $6 \mathrm{~h}$ ) para que o modelo se estabilize e não produza precipitações não realísticas, fato que também foi comprovado pela avaliação estatística.

A assimilação dos dados de razão de mistura de água de chuva (a partir da refletividade) e de vento radial produziram modificações representativas nas análises de altos e baixos níveis, bem como no perfil vertical do modelo. Consequentemente esta diferença na nova condição inicial se propagou durante a previsão. A previsão utilizando ADR apresentou um campo de precipitação mais semelhante ao observado e obteve os melhores resultados ao posicionar os núcleos de precipitação intensa, mostrando a importância e o ganho ao assimilar os dados de radar. As alterações no campo de precipitação em geral ficaram restritas à área de cobertura dos dados de radar.

A avaliação estatística provou que a previsão utilizando a ADR obteve os melhores resultados ao posicionar os núcleos de precipitação intensa, porém com maior erro de magnitude associado, indicando superestimativa em alguns valores. Através dos valores de FSS encontrados, que no geral, a ADR melhorou o posicionamento da previsão de $6 \mathrm{~h}$ de precipitação. Houve ganho ao assimilar os dados de radar, ou manteve-se igual ao modelo sem assimilar estes dados, mostrando que ao assimilar o radar não há perda, embora em algumas rodadas o ganho seja pequeno. Um maior número de casos precisa ser analisado para afirmar com grande confiabilidade as hipóteses citadas.

O estudo deste SCM intenso é útil para analisar as características e possíveis erros recorrentes na previsão determinística de precipitação, embora não seja suficiente para generalizar para todos os SCM. 


\section{Agradecimentos}

Os autores agradecem ao SIMEPAR pelo apoio e disponibilização dos dados e aos projetos 400065/2014-2 e 400045/2014-1 do Conselho Nacional de Desenvolvimento Científico e Tecnológico (CNPq). A primeira autora agradece a CAPES pela bolsa de mestrado concedida e a Pós Graduação em Meteorologia do INPE.

\section{Referências}

CRAIG, G.C.; KEIL, C.; LEUENBERGER, D. Constraints on the impact of radar rainfall data assimilation on forecasts of cumulus convection. Quarterly Journal of the Royal Meteorological Society, v. 138, n. 663, p. 340-352, 2012.

DUDHIA, J. Numerical study of convection observed during the winter monsoon experiment using a mesoscale two-dimensional model. Journal of Atmospheric Science, v. 46, p. 3077-3107, 1989.

FERREIRA, R.C. Estudo de Sistemas Convectivos de Mesoescala com uso de assimilação de dados de radar. Dissertação de Mestrado em Meteorologia. Instituto Nacional de Pesquisas Espaciais, São José dos Campos, 2016.

FERREIRA, R.C.; HERDIES, D.L.; VILA, D.A.; BENETI, C.A.A. Combination of satellite precipitation estimates and rain gauge for high spatial and temporal resolutions. 20th International Tovs Study Conference (ITSC). ITSC-XX Lake Geneva, Wisconsin, USA. 2015. Disponível em: https://cimss.ssec.wisc.edu/itwg/itsc/itsc20/papers/8p_10_herdies_paper.pdf. Acesso em: 2016-11-04.

FERREIRA, R.C.; HERDIES, D.L.; VILA, D.A.; ROZANTE, J.R.; SOUZA, D.O.; BENETI, C.A.A.; BISCARO, T.S. Avaliação de estimativas de precipitação combinadas em alta resolução espacial e temporal In: Anais XIX Congresso Brasileiro de Meteorologia. João Pessoa. 2016.

HONG, S.Y.; LIM, K.S.S. The WRF Double Moment Cloud Microphysics Scheme (WDM). 2009. Disponível em: http://www2.mmm.ucar.edu/wrf/users/workshops/WS2009/presentations/5B06.pdf Acesso em: 2016-01-02.

LIM, K.S. S; HONG, S.Y. Development of an effective double moment cloud microphysics scheme with prognostic cloud condensation nuclei $(\mathrm{CCN})$ for weather and climate models. Monthly Weather Review, v. 138, n. 5, p. 15871612, 2010.

MACHADO, L.A.T.; ROSSOW, W.B.; GUEDES, R.L.; WALKER, A.W. Life cycle variations of mesoscale convective systems over the Americas. Monthly Weather Review, v. 126 , n. 6, p. 1630-1654, 1998.
MADDOX, R.A. Mesoscale convective complexes. Bulletin of the American Meteorological Society, v. 61, n. 11, p. 1374-1387, 1980.

PARRISH, D.F.; DERBER, J.C. The National Meteorological Center's spectral statistical-interpolation analysis system. Monthly Weather Review, v. 120, n. 8, p. 1747-1763, 1992.

SOKOL, Z. Assimilation of extrapolated radar reflectivity into a NWP model and its impact on a precipitation forecast at high resolution. Atmospheric Research, v. 100, n. 2, p. 201-212, 2011.

VEBER, M.E., ROCHA, F.P. Análise Preliminar da Previsão de Rajadas de Vento Pelo Modelo Numérico WRF $1 \mathrm{~km}$ Durante os Jogos Olímpicos RIO 2016. In: Anais XIX Congresso Brasileiro de Meteorologia. João Pessoa. 2016.

VELASCO, I.; FRITSCH, J.M. Mesoscale convective complexes in the Americas. Journal of Geophysical Research: Atmospheres (1984-2012), v. 92, n. D8, p. 9591-9613, 1987.

VENDRASCO, E.P., SUN, J., HERDIES, D.L., ANGELIS, C.F. Constraining a 3DVAR radar data assimilation system with large-scale analysis to improve short-range precipitation forecasts. Journal of Applied Meteorology and Climatology, v. 55, n. 3, p. 673-690, 2016.

VILA, D.A., GONCALVES, L.G. G., TOLL, D.L., ROZANTE, J.R. Statistical evaluation of combined daily gauge observations and rainfall satellite estimates over continental South America. Journal of Hydrometeorology, v. 10, n. 2, p. 533-543, 2009.

WANG, H.; SUN, J.; FAN, S.; HUANG, X.Y. Indirect assimilation of radar reflectivity with WRF 3d-var and its impact on prediction of four summertime convective events. J. Appl. Meteor. Climat., v. 52, p. 889-902, 2013.

XIAO, Q.; SUN, J. Multiple-radar data assimilation and short-range quantitative precipitation forecasting of a squall line observed during IHOP 2002. Monthly Weather Review, v. 135, n. 10, p. 3381-3404, 2007.

ROBERTS, N.; LEAN, H. Scale-selective verification of rainfall accumulations from high-resolution forecasts of convective events. Monthly Weather Review, v. 136, p. 78-97, 2008.

WARNER, T.T., Numerical weather and climate prediction. Cambridge University Press, 2011.

SKAMAROCK, W.C.; KLEMP, J.B.; DUDHIA, J.; GILL, D.O.; BARKER, D.M.; DUDA, M.G.; HUANG, X.; WANG, W.; POWERS, J.G. A description of the advanced research WRF version 3. National Center for Atmospheric Research, 2008. 125 p. NCAR TECHNICAL NOTE.

This is an Open Access article distributed under the terms of the Creative Commons Attribution Non-Commercial License which permits unrestricted non-commercial use, distribution, and reproduction in any medium provided the original work is properly cited. 